\title{
Optimizing Design of Core-clad Width for Single Mode Fiber with Zero Dispersion Shift
}

\author{
Toto Saktioto \\ Dept. of Physics \\ Universitas Riau \\ Pekanbaru, Indonesia \\ saktioto@ieee.org \\ Romi Fadli Syahputra \\ Dept. of Physics \\ Universitas Riau \\ Pekanbaru, Indonesia \\ romifadlisyahputra@yahoo.com
}

\author{
Doni Basdyo \\ Dept. of Physics \\ Universitas Riau \\ Pekanbaru, Indonesia \\ donibasdyo@gmail.com \\ Okfalisa Okfalisa \\ Dept. of Science and Technology \\ Universitas Islam Negeri Suska \\ Pekanbaru, Indonesia \\ okfalisa@gmail.com \\ Syamsudhuha \\ Dept. of Mathematics \\ Universitas Riau \\ Pekanbaru, Indonesia \\ syamsudhuha@yahoo.com
}

\author{
Yoli Zairmi \\ Dept. of Physics \\ Universitas Riau \\ Pekanbaru, Indonesia \\ yolizairmi12@gmail.com \\ Wresni Anggraini \\ Dept. of Science and Technology \\ Universitas Islam Negeri Suska \\ Pekanbaru, Indonesia \\ wresnilanggraini@gmail.com
}

\begin{abstract}
Fiber optics have become a vital role in telecommunication technologies with many benefits, i.g. high speed transmission, non-electromagnetic interference and low energy consumption. An excellent single mode fiber (SMF) must provide a low attenuation and dispersion which occurs at same wavelength, i.e. $1550 \mathrm{~nm}$. But, in silica based SMF, this property cannot be achieved in a bulk form. Meanwhile, the direct experiment is really not the best choice. Therefore, a simulation fiber design take a crucial role into account for obtaining zero dispersion shift. We design SMF geometry with zero dispersion by resizing the width of core and cladding. This design consists of inner and outer core-clad profile. We also provide several width boundaries for matching the lowest dispersion to the lowest attenuation in silica fiber-based. Moreover, the results shows that dispersion property of the design is suitable for long-haul optical communication systems.
\end{abstract}

\section{Keywords-Optical design, Single mode fiber, Zero dispersion shift}

\section{INTRODUCTION}

Telecommunication system development has grown in impressive way, transmitting any information from long distance in a second by utilizing fiber optic network. Recently, fiber optics (FO) is boosted to transmit a huge byte of information to approach the fundamental limit about 100-200 Tbit/s using single mode fiber (SMF) [1,2]. FO network is high speed transfer, immunity to electromagnetic interference, and non corrosive materials [3-5]. Meanwhile, power losses and dispersion are still problematic issue in developing SMF for higher frequencies [6,7]. Optimization of design is a better step and important part in fiber manufacturing in order to suppress the cost of fabrication and its maintenances [4,8-12].

This study provides a simulation to obtain a better design of dispersion-shifted fiber (DSF). The design consists of double core-clad layer, i.e. inner and outer core, and inner and outer cladding. We investigate a role of width of inner and outer core in order zero dispersion width (ZDW) occurs around $1.55 \mu \mathrm{m}$, wavelength of the lowest attenuation in silica fiber [6,7]. This fiber is proposed for SMF application in long distance fiber communication.

\section{DESIGN AND OPERATION}

We use Optifiber ${ }^{\circledR}$ for designing the fibers. A cross section of the fiber is given in Fig. 1. The fiber consist of four regions, i.e. inner core (region 1), inner cladding (region 2), outer core (region 3), and outer cladding (region 4). The refractive index of each region is provided in Tabel 1.

\begin{tabular}{cc} 
TABLE 1. REFRACTIVE INDEX OF EACH REGION \\
\hline Region & Refractive index \\
\hline Inner core & $1.4615-1.44692$ \\
Outer core & 1.44692 \\
Inner cladding & 1.45 \\
Outer cladding & 1.44692 \\
\hline
\end{tabular}

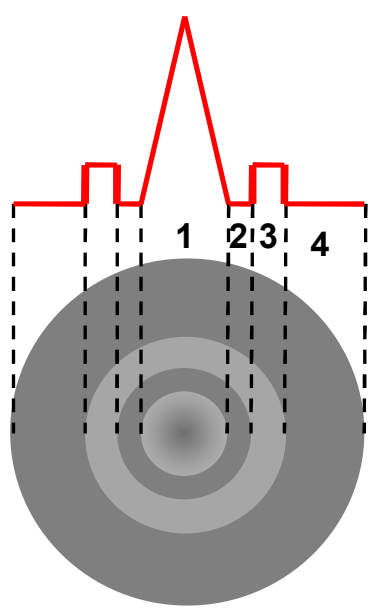

Fig. 1. Proposed design of the fiber. The number indicate the region: 1 is inner core, 2 is inner cladding, 3 is outer core and 4 is outer cladding. Red line depicts refractive index distribution. 
The terms of inner and outer represent radial sequence of core or cladding from the center of fiber. Higher refractive index is denoted as core, and the lower as cladding. The regional section of the proposed design following these boundaries.

Region 1:

$$
n(r)=n_{1}+\left(\frac{n\left(w_{1}\right)-n_{1}}{w_{1}}\right) r \quad, \quad 0 \leq r \leq w_{1}
$$

Region 2:

$$
n(r)=n_{2} \quad, \quad w_{1} \leq r \leq w_{2}
$$

Region 3:

$$
n(r)=n_{3} \quad, \quad w_{2} \leq r \leq w_{3}
$$

Region 4:

$$
n(r)=n_{4} \quad, \quad w_{3} \leq r \leq w_{4}
$$

with $r$ is radii, $w_{i}$ and $n_{i}$ indicate refractive index of each region, respectively. For region 1 (inner core), refractive index will be graded in 100 steps as indicated by linear gradient in equation (1). Width of inner core are varied for $1.0,2.0$, and $3.0 \mu \mathrm{m}$. While the outer core are 0.5, 1.0, 1.5, and $2.0 \mu \mathrm{m}$. The size of inner cladding is set constant at $1.5 \mu \mathrm{m}$ and over all radii of the fiber are also set constant for $65 \mu \mathrm{m}$. This means that the size of outer cladding depends upon size of inner and outer core.

In order to comprehend the waves behavior and their interaction with the waveguide so that a group delay, dispersion, and effective refractive index of the design will be analyzed. Zero dispersion analysis is obtained by tracing the dispersion line over wavelength. The initial value of the lowest dispersion of silcon fiber is $1.3 \mu \mathrm{m}[6,7]$. Wavelength range is from $1.3 \mu \mathrm{m}$ until $1.7 \mu \mathrm{m}$ in 5000 steps. This dispersion represents the sum of dispersion of waveguide and material.

\section{RESULT AND DISCUSSION}

\section{A. Group delay profile}

Group delay property is another important parameter in fiber technology, specially for modulation signal [13]. Group delay depends upon frequency, waveguide structure and the material property [3-5]. As shown figures from Fig. 2, the delays can be decreased or increased over width of inner and outer core changes. When the core width is constant at 1.0 $\mu \mathrm{m}$, increasing the outer size can raise the lowest point of group delay. But, at $3.0 \mu \mathrm{m}$ inner core, the lowest group delay decreases by increasing size of outer core. Meanwhile, for $2.0 \mu \mathrm{m}$ inner core, the lowest group delay is fluctuative.

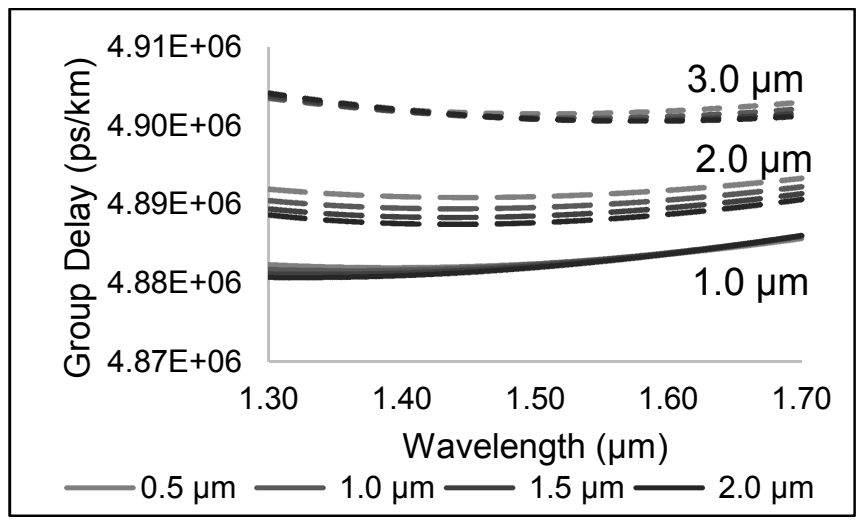

Fig. 2. Group delay profile for inner core of $1.0 \mu \mathrm{m}$ (solid line), $2.0 \mu \mathrm{m}$ (long dash line) and $3.0 \mu \mathrm{m}$ (dash line).

\section{B. Dispersion profile}

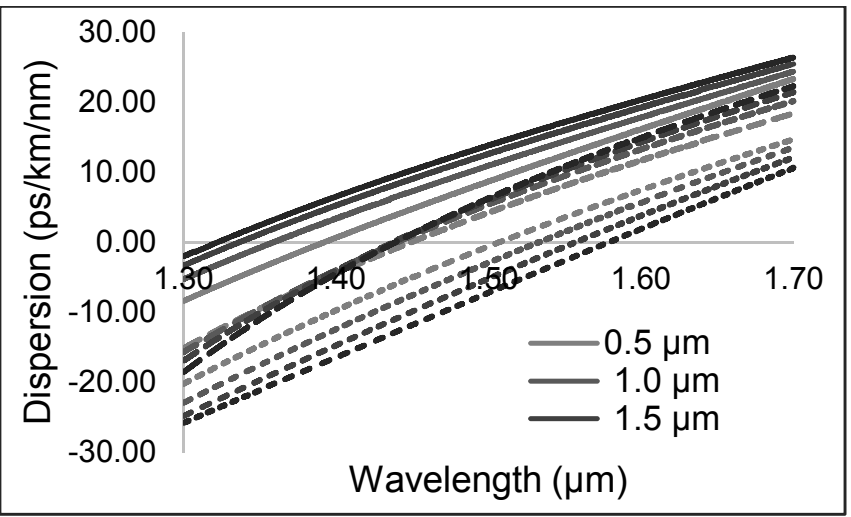

Fig. 3. Dispersion profile for inner core of $1.0 \mu \mathrm{m}$ (solid line), $2.0 \mu \mathrm{m}$ (long dash line) and $3.0 \mu \mathrm{m}$ (dash line).

Dispersion in optical waveguide is caused by different velocity of light which produce dilation of signal frequency. Dispersion results light pulses to be wider and overlap with each other, so the information carried by these pulses are to be damage [5]. In zero dispersion condition, the pulses will be transmitted safely and easy to demodulation by the receiver $[9,13]$.

TABLE 2. ZERO DISPERSION SHIFT

\begin{tabular}{ccc}
\hline \multicolumn{2}{c}{ Width of core $(\mu \mathrm{m})$} & $\begin{array}{c}\text { ZDW, } \lambda_{0} \\
(\mu \mathrm{m})\end{array}$ \\
\cline { 1 - 2 } inner & outer & 1.3919 \\
\multirow{2}{*}{1.0} & 0.5 & 1.3584 \\
& 1.0 & 1.3360 \\
& 1.5 & 1.3222 \\
\hline \multirow{3}{*}{2.0} & 2.0 & 1.4478 \\
& 0.5 & 1.4393 \\
& 1.0 & 1.4368 \\
& 1.5 & 1.4379 \\
\hline \multirow{3}{*}{3.0} & 2.0 & 1.5062 \\
& 0.5 & $\mathbf{1 . 5 3 1 6}$ \\
& $\mathbf{1 . 0}$ & $\mathbf{1 . 5 5 5 6}$ \\
& $\mathbf{1 . 5}$ & 1.5780 \\
\hline
\end{tabular}

Our proposed fibers are shown a single ZDW for interval 1.3-1.7 $\mu \mathrm{m}$. As depicted in Fig. 3 and Table 2, there is trend of dispersion shift by increasing size of inner and outer core. If the inner core is set to $1.0 \mu \mathrm{m}$ and outer core width is varied from 0.5 to $2.0 \mu \mathrm{m}$, the $\mathrm{ZDW}$ decreases to be lower than 1.37 shift, which the natural ZDW of bulk silica glass. Meanwhile, if width inner core is $3.0 \mu \mathrm{m}$, the ZDW will shift to higher wavelength. At this inner core size, there is found that the ZDW may obtain in outer core range of 1.0-1.5 $\mu \mathrm{m}$ which deals with lowest attenuation window for silica fiber around $1.55 \mu \mathrm{m}[6,7]$. For inner core $2.0 \mu \mathrm{m}$, the $\mathrm{ZDW}$ is only slight changes arround $1.44 \mu \mathrm{m}$. These results also proof that size and kind of structures are straight forward to optical properties of waveguide as found in photonic crytal [14-17] and metamaterial [18-20]. 


\section{Optimized Design}

Finally, we have designed and operated the optimized fiber to obtain ZDW about $1.55 \mu \mathrm{m}$ for matching with the lowest attenuation of silica fiber. The refractive index distribution is shown in Fig 9. The designed fiber is similar to refractive index profile, but we choose the width of inner and outer core around $3.0 \mu \mathrm{m}$ and $2.0 \mu \mathrm{m}$, respectively, as suggested in preceding section. Optimized fiber design has inner core of $3.0 \mu \mathrm{m}$, inner cladding of $1.4 \mu \mathrm{m}$, outer core of $1.55 \mu \mathrm{m}$ and outer cladding of $59.1 \mu \mathrm{m}$.

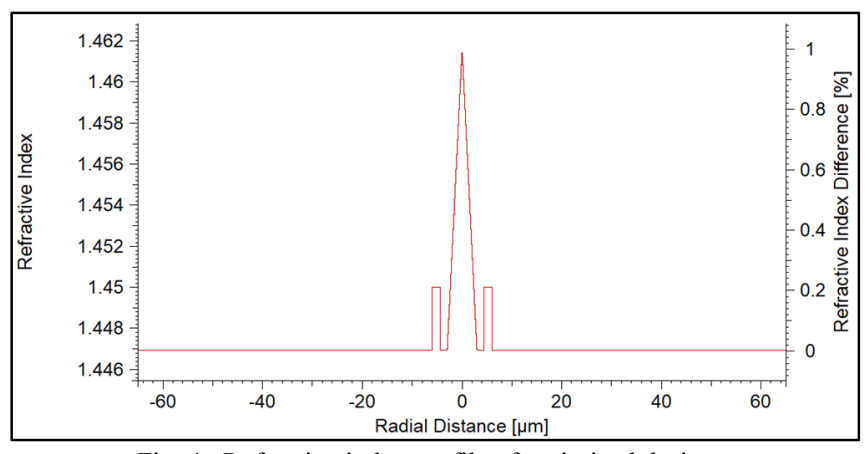

Fig. 4. Refractive index profile of optimized design.

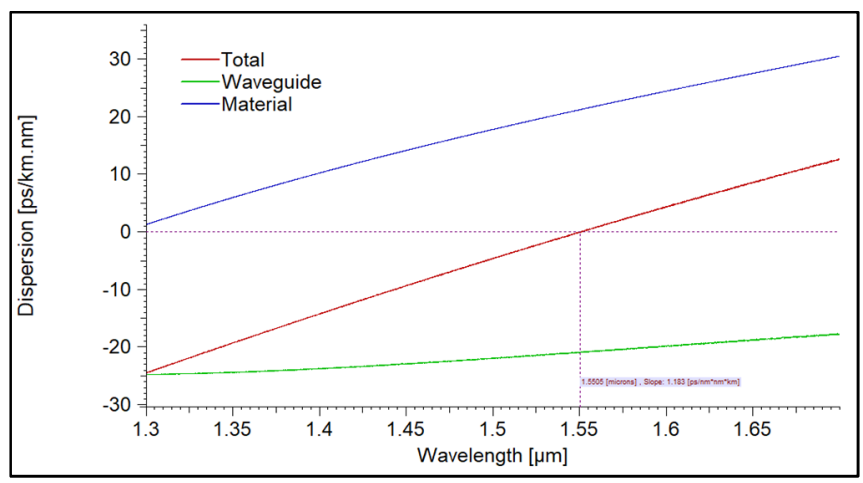

Fig. 5. ZDW of optimized design

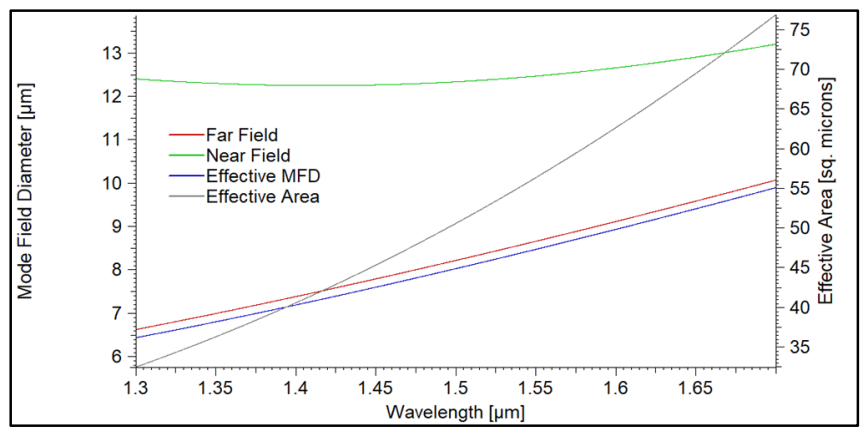

Fig. 6. MFD and effective area of optimized design.

The optimized design describes that ZDW can occur at wavelength of $1.5505 \mu \mathrm{m}$ as depicted in Fig 5. It is less of $0.5 \%$ from $1.55 \mu \mathrm{m}$. Moreover, mode field diameter (MFD) indicates that the design is reliable for single mode waveguide both for near or far field scheme with high effective MFD about $45 \mu \mathrm{m}^{2}$ at wavelength of $1.55 \mu \mathrm{m}$ as depicted in Fig. 6. The large MFD is required for transmitting high power signal without any nonlinearity effects for long transmission distance $[21,22]$.

\section{CONCLUSION}

The optimized design of fiber optics with ZDW around $1.550 \mathrm{\mu m}$ has been simulated by arranging size of core-clad, where core-clad size is much dependent. The better design zero dispersion shift is obtained at $1.5505 \mu \mathrm{m}$ by configuration of $3.0 \mu \mathrm{m}$ inner core, $1.4 \mu \mathrm{m}$ inner cladding, $1.55 \mu \mathrm{m}$ outer core and $59.1 \mu \mathrm{m}$ outer cladding. MFD and effective area of the design are sufficiently high and suitable for high performance of SMF.

\section{ACKNOWLEDGMENT}

We would like to thank The Ministry of Research, Technology and Higher Education through Universitas Riau for generous support in this research with the Basic Competitive Research Grant in 2019.

\section{REFERENCES}

[1]. Sano, T. Kobayashi, E. Yoshida, A. Miyamoto, "Ultra-high capacity optical transmission technologies for $100 \mathrm{Tbit} / \mathrm{s}$ optical transport networks," IEICE T. Commun., vol. E94-B. pp. 400-408, 2011.

[2]. E. Agrell, M. Karlsson, A.R. Chraplyvy, D.J. Richardson, P.M. Krummrich, P. Winzer, et al., "Roadmap of optical communications," J. Opt., vol. 18, article number 063002, 2016.

[3]. Giallorenzi, T.G., Bucaro, J.A., Dandridge, A., Sigel, G.H., Jr., Cole, J.H., Rashleigh, S.C., Priest, R.G. Optical Fiber Sensor Technology. IEEE J. Quantum Electron, vol. QE -18, pp. 626-665, 1982.

[4]. Rajiv Ramaswami, Kumar N. Sivarajar, Galen H. Sasaki. Optical Networks (Third Edition)- A Practical Perspective: Chapter 3 Propagation of Signals in Optical Fiber, pp. 47-112, 2009.

[5]. J. Crisp and B. Elliott, Introduction to Fiber Optics, third ed. Amsterdam, Netherland: Elsevier, 2005.

[6]. T. D. Croft, J. E. Ritter, and V. A. Bhagavatula, "Low-loss dispersion-shifted single-mode fiber manufactured by the OVD process,” J. Lightwave Technol., vol. LT-3, October 1985.

[7]. S. Kedenburg, T. Steinle, F. Mörz, A. Steinmann, D. Nguyen, D. Rhonehouse, J. Zong, A. Chavez Pirson, and H. Giessen, "Solitonic supercontinuum of femto second mid-IR pulses in W-type index tellurite fibers with two zero dispersion wavelengths," APL Photonics, vol 1, Article ID 086101, 2016.

[8]. A.J. Lowery and J. Armstrong, "Orthogonal-frequency-division multiplexing for dispersion compensation of long-haul optical systems," Opt Express, vol. 14, pp./ 2079- 2084, March 2006.

[9]. Saktioto, J. Ali, M. Fadhali, R. A. Rahman, and J. Zainal, "Modeling of coupling coefficient as a function of coupling ratio," Proc. SPIE, vol 7155, Article number 71551P, 2008.

[10]. S. Warm, C.-A. Bunge, T, Wuth, and K, Petermann, "Electronic Dispersion Precompensation With a10-Gb/s Directly Modulated Laser," IEEE Photon. Technol. Lett., vol. 21, pp. 1090- 1092, August 2009.

[11]. S. O. Mohammadi, S. Mozzaffari, and M. M. Shahidi,"Simulation of a transmission system to compensate dispersion in an optical fiber by chirp gratings," Int. J. Phys. Sci., vol. 6, pp. 7354 - 7360, December 2011.

[12]. R. F. Syahputra, Saktioto, R. Meri, Syamsudhuha, and Okfalisa, "Profile of single mode fiber coupler combining with Bragg grating," Telkomnika, vol. 15, pp. 1103-1107, 2017.

[13]. K. Y. Song, M. G. Herráez and L. Thévenaz, "Observation of pulse delaying and advancement in optical fibers using stimulated Brillouin scattering," Opt. Express, vol. 3, pp. 82-88, 2004.

[14]. S. Olyaee F. Taghipour, "Ultra-flattened dispersion hexagonal photonic crystal fibre with low confinement loss and large effective area," IET Optoelectron., vol. 6, pp. 82-87, 2012.

[15]. H. Xu, J. Wu, K. Xu, Y. Dai, and J. Lin, "Highly nonlinear all-solid photonic crystal fibers with low dispersion slope," Appl. Opt., vol. 51, 1021-1027, 2012.

[16]. Y.-C. Shuai, D. Zhao, Y. Liu, C. Stambaugh, and J. Lawall, W. Zhou, "Coupled bilayer photonic crystal slab electro-optic spatial light modulators," IEEE Photonics J., vol. 9, Article number 7866012, April 2017 
[17]. O. Jaworska and S. Ertman, "Photonic bandgaps in selectively filled photonic crystal fibers," Photonics Lett. Pol., 9(3), pp. 79-81, 2017.

[18]. R. A. Shelby, D. R. Smith, and S. Schultz, "Experimental verification of a negative index of refraction," Science, 292, pp. 77 79, 2001.

[19]. J. B. Pendry, D. Schurig, and D. R. Smith, "Controlling electromagnetic fields" Science, vol. 312, pp. 1780-1782, 2006.

[20]. T. Saktioto, R. F. Syahputra, S. Punthawanunt, J. Ali, and P. Yupapin, "GHz frequency filtering source using hexagonal metamaterial splitting ring resonators," Microw. Opt. Technol. Lett., vol. 59, pp. 1337-1340, 2017.

[21]. M. Koshiba and K. Saitoh, "Structural dependence of effective area and mode field diameter for holey fibers," Opt. Express, vol. 11, pp. 1746-1756, 2003.

[22]. D. K. Sharma and A. Sharma, "On the mode field diameter of microstructured optical fibers," Opt. Commun., vol. 291, pp. 162168, 2013. 